\title{
Constraining the impact of the varying seawater calcium to sulfate ratio on authigenic carbonate precipiation over the Phanerozoic

\author{
HAROLD J BRADBURY
}

University of Cambridge

Presenting Author: hjb62@cam.ac.uk

The removal of carbon from the surface of the planet is a critical component of the long-term carbon cycle; this removal is through the deposition and subsequent burial of organic carbon and carbonate minerals in the ocean. Sedimentary, postdepositional processes play a key role in the global carbon cycle because much of the organic carbon in sediments is microbially oxidized back to dissolved inorganic carbon. The oxidation of organic carbon in anoxic sediment through the reduction of sulfate can consume protons, raising $\mathrm{pH}$, and leading to some of the dissolved inorganic carbon precipitating as in situ, or authigenic carbonate. As this authigenic carbonate has a different carbon isotope composition to marine carbonate, it may influence the overall carbon isotope balance at Earth's surface and critically, our interpretation of global shifts in the carbon cycle over geological time. The seawater sulfate concentration varies significantly through the Phanerozoic, which shifts the depth and relative intensity of the zones of organic carbon oxidation. When this effect is combined with the changing calcium concentrations over the Phanerozoic there is a significant influence on the saturation state of carbonate minerals in the sedimentary pore fluid. We use a reactive transport model to investigate how variations in seawater sulfate and calcium concentration has impacted the precipitation of authigenic carbonate, and hence the carbon cycle, over the Phanerozoic.

Modern environments hold the clues as to where and how carbon mineralisation occurs. They also may hold clues to the microscale variability in carbonate rocks that then feed into proxies which are the weighted average of their various constituents. One question that has been less addressed is how changes in the calcium to sulfate ratio over the Phanerozoic may have impacted the amount and distribution of sedimentary carbonate phases, given that the relative amount of calcium and sulfate are key variables in the subsurface precipitation of carbonate minerals. The modelling will explore how in times of different calcium to sulfate ratio sediments may be poised towards more carbonate mineral precipitation and thus larger degrees of microscale variability. 